\title{
Unusual respiratory manifestations in two young adults with Duchenne muscular dystrophy
}

\author{
Julie Lemay $M D^{1}$, Frédéric Sériès $M D^{1}$, Mario Sénéchal $M D^{1}$, Bruno Maranda $M D^{2}$, François Maltais $M D^{1}$
}

\begin{abstract}
J Lemay, F Sériès, M Sénéchal, B Maranda, F Maltais. Unusual respiratory manifestations in two young adults with Duchenne muscular dystrophy. Can Respir J 2012;19(1):37-40.

Adult respirologists are often involved in the evaluation and treatment of young adult patients with Duchenne muscular dystrophy. In this context, the most frequent respiratory complication is nocturnal and daytime hypoventilation related to respiratory muscle weakness. The present article describes cases of Duchenne muscular dystrophy involving two brothers, 17 and 19 years of age, respectively, who presented with less frequently reported respiratory complications of their disease: obstructive sleep apnea and Cheyne-Stokes respiration with central apnea, which were believed to be partially or completely related to congestive cardiomyopathy.
\end{abstract}

Key Words: Cheynes-Stokes respiration; Duchenne muscular dystrophy; Sleep apnea

uchenne muscular dystrophy (DMD) is an X-linked neuromuscular disease that predominantly affects skeletal and cardiac muscle. DMD has an incidence of approximately one in 3000 male births and is caused by mutation of the dystrophin gene (1). DMD is characterized by the absence of dystrophin and, in many patients, the progression of the disease is predictable. In affected boys, ambulatory capacity usually begins to decrease between 10 and 12 years of age. Without treatment, patients develop progressive hypercapnic respiratory failure related to respiratory muscle weakness and, in most patients, life expectancy is less than 20 years. Long-term noninvasive ventilation is commonly used to limit the consequences of respiratory failure and to prolong survival (2). DMD can also be associated with other types of respiratory manifestations, such as obstructive sleep apnea (OSA), which is typically observed before 10 years of age (3). Cardiac involvement is also common in these patients. Although it may lead to mortality, cardiac involvement related to DMD can usually be treated, with optimal benefit if appropriate medication is initiated early after the diagnosis of left ventricular systolic dysfunction $(4,5)$. The present report describes cases of two DMD brothers who, at the end of their teenage years, presented with respiratory manifestations that were believed to be partially or completely related to congestive cardiomyopathy.

\section{CASE PRESENTATION}

Case 1

The older brother was born in September 1988. He came to medical attention at two years of age for locomotor impairment, language delay and cognitive difficulties. DMD was suspected on the basis of elevated creatine kinase levels, and subsequently confirmed by muscular biopsy showing the absence of dystrophin. Genetic testing using multiplex polymerase chain reaction revealed the deletion of exons 12 and 13 of the dystrophin gene. The familial pedigree of the three previous generations did not show neuromuscular disorder.

Despite progressive muscle weakness, the patient was able to walk until he was 15 years of age. Even at this age, he remained autonomous in the transfer from wheelchair to bed, and able to move into bed, which is unusual for DMD patients in this age category. Prednisone was not recommended because of potential side effects that could outweigh potential benefits.

\author{
Des manifestations respiratoires inhabituelles chez \\ deux jeunes adultes ayant une dystrophie \\ musculaire de Duchenne
}

Les pneumologues pour adultes participent souvent à l'évaluation et au traitement de jeunes patients adultes ayant une dystrophie musculaire de Duchenne. La principale complication respiratoire qu'ils observent alors est une hypoventilation nocturne et diurne liée à la faiblesse des muscles respiratoires. Le présent article décrit les cas de dystrophie musculaire de Duchenne de deux frères de 17 et 19 ans, respectivement, qui présentaient des complications respiratoires moins courantes de leur maladie, soit une apnée obstructive du sommeil et une respiration de Cheyne-Stokes accompagnée d'apnée centrale, qu'on croyait partiellement ou entièrement liées à une myocardiopathie congestive.

A cardiomyopathy was diagnosed at 14 years of age; transthoracic echocardiography revealed a decreased left ventricular ejection fraction (LVEF) (50\%) and a mild left ventricular end-diastolic dilation (54 mm). Lisinopril was introduced at $2.5 \mathrm{mg}$ once daily. Despite this treatment, LVEF continued to decline. Lisinopril was progressively increased to $10 \mathrm{mg}$ daily. At 17 years of age, his LVEF was 32\% and the left enddiastolic dimension showed a moderate to severe dilation $(64 \mathrm{~mm})$.

The patient was hospitalized in another institution at 19 years of age because of dyspnea that was attributed to an episode of decompensated dilated cardiomyopathy (DCM). A transthoracic echocardiogram showed severe biventricular systolic dysfunction, with an LEVF of $15 \%$ and a significantly dilated left ventricle $(72 \mathrm{~mm})$; a severe functional mitral insufficiency was also observed. Lisinopril was increased from $10 \mathrm{mg}$ to $15 \mathrm{mg}$ daily, and furosemide was introduced. The patient progressively improved with treatment. Nocturnal oximetry showed repeated transient desaturations, which were not further characterized. Fortythree per cent of the night was spent with an oxygen pulse saturation $\left(\mathrm{SpO}_{2}\right)<90 \%$. Nocturnal oxygen was initiated at $1 \mathrm{~L} / \mathrm{min}$, which corrected the nocturnal desaturations.

The patient was then transferred to the Institut Universitaire de cardiologie et de pneumologie de Québec and evaluated by a respirologist. Pulmonary function was surprisingly well preserved for a boy of his age. A moderate pulmonary restrictive disorder with respiratory muscle weakness was diagnosed (Table 1). His maximal inspiratory pressure was $-53 \mathrm{cmH}_{2} \mathrm{O}$ (40\% predicted [6]) and the maximal expiratory pressure was $+65 \mathrm{cmH}_{2} \mathrm{O}(26 \%$ predicted [6]). His daytime partial pressure of arterial carbon dioxide $\left(\mathrm{PaCO}_{2}\right)$ ranged from $30 \mathrm{mmHg}$ to $35 \mathrm{mmHg}$, with normal bicarbonate levels.

A new nocturnal oximetry recording was performed with room air and showed recurrent and transient episodes of desaturation. His desaturation index was $48 / \mathrm{h}$. His basal $\mathrm{SpO}_{2}$ was $93 \%$, with a minimum of $76 \%$. Thirty-four per cent of the night was spent with $\mathrm{SpO}_{2}<90 \%$. Nocturnal cardiorespiratory monitoring (Embletta, Embletta, USA) showed that episodes of $\mathrm{O}_{2}$ desaturations were all related to nonobstructive breathing disturbances, with a total index of $37 / \mathrm{h}$. This recording showed characteristic features of Cheyne-Stokes respiration with central apneas during sleep (Figure 1). Although level III sleep monitoring has not been validated in patients with neuromuscular

${ }^{1}$ Centre de recherche, Institut Universitaire de cardiologie et de pneumologie de Québec, Université Laval; ${ }^{2}$ Service de génétique médicale,

Université de Sherbrooke, Quebec

Correspondence: Dr François Maltais, Institut Universitaire de cardiologie et de, pneumologie de Québec, 2725 Chemin Ste-Foy, Québec,

Québec G1V 4G5. Telephone 418-656-4747, fax 418-656-4762, e-mail francois.maltais@med.ulaval.ca 


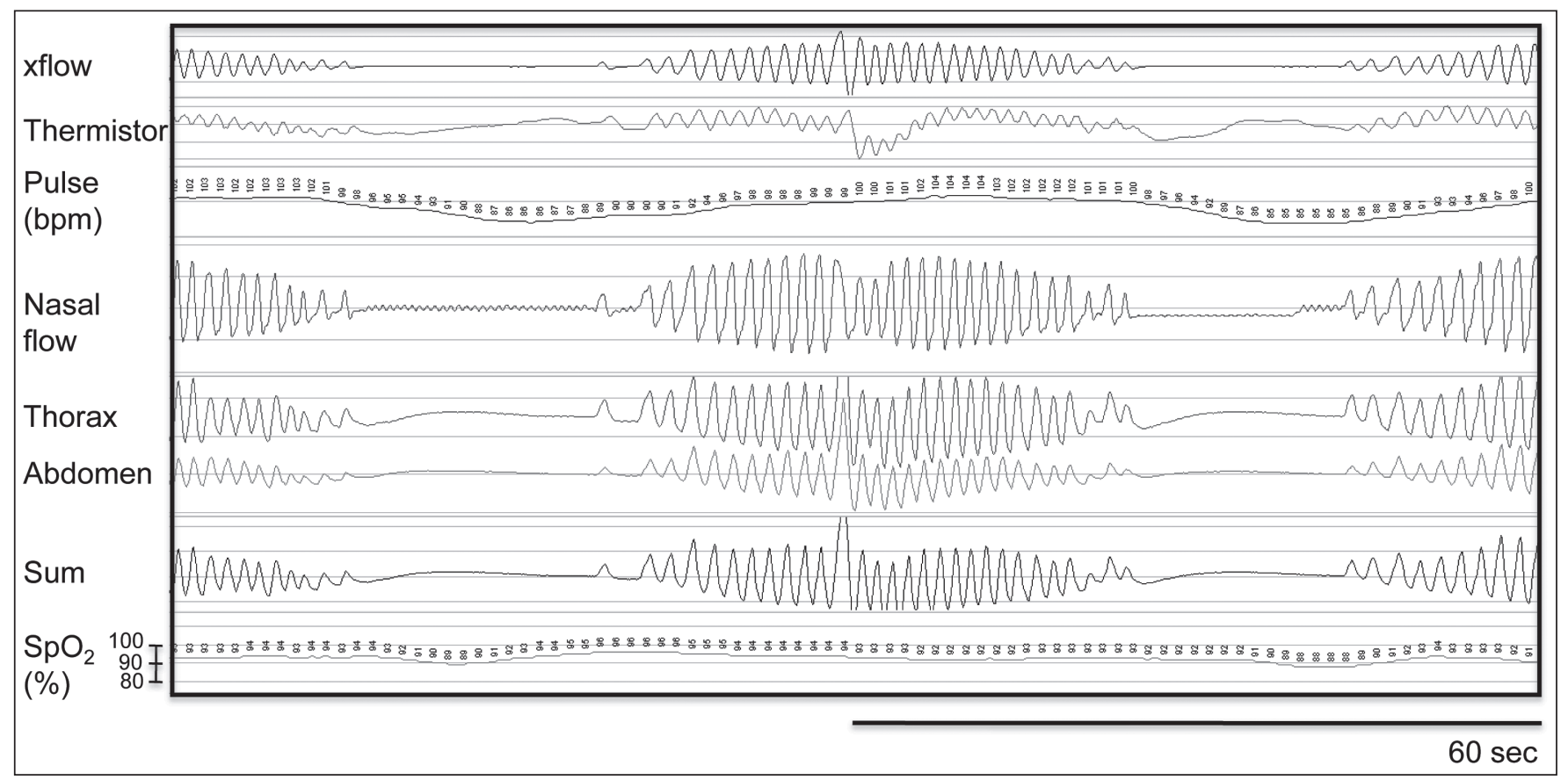

Figure 1) Representative nocturnal cardiorespiratory tracing (Embletta, Embletta, USA) showing a typical episode of Cheyne-Stokes respiration with central apneas during sleep. bpm Beats per min; $\mathrm{SpO}_{2}$ Pulse oxygen saturation

TABLE 1

Physical characteristics and pulmonary function data

\begin{tabular}{|c|c|c|}
\hline & \multicolumn{2}{|c|}{ Brother } \\
\hline & 19 years of age & 17 years of age \\
\hline Height, $\mathrm{cm}$ & 174 & 167 \\
\hline Weight, kg & 84 & 68 \\
\hline Body mass index, $\mathrm{kg} / \mathrm{m}^{2}$ & 27 & 24 \\
\hline FVC, L (\% predicted) & $3.06(56)$ & $4.18(97)$ \\
\hline $\mathrm{FEV}_{1}, \mathrm{~L}(\%$ predicted $)$ & $2.39(52)$ & $3.96(112)$ \\
\hline $\mathrm{FEV}_{1} / \mathrm{FVC}, \%$ & 78 & 95 \\
\hline FRC, L (\% predicted) & $1.79 \mathrm{~L}(55)$ & $2.51 \mathrm{~L}(101)$ \\
\hline DLCO, \% predicted & 75 & 124 \\
\hline MIP, $\mathrm{cmH}_{2} \mathrm{O}$ (\% predicted) & $-53(40)$ & - \\
\hline MEP, $\mathrm{cmH}_{2} \mathrm{O}(\%$ predicted $)$ & $+65(26)$ & - \\
\hline $\mathrm{PaCO}_{2}, \mathrm{mmHg}$ & 35 & 42 \\
\hline
\end{tabular}

DLCO Diffusing capacity for carbon monoxide; FEV ${ }_{1}$ Forced expiratory volume in $1 \mathrm{~s}$; FRC Functional residual capacity; FVC Forced vital capacity; MEP Maximal expiratory pressure; MIP Maximal inspiratory pressure; $\mathrm{PaCO}_{2}$ Partial pressure of arterial carbon dixide

conditions, the tracing was typical for Cheyne-Stokes respiration with central apnea/hypopneic events. These events were followed by a progressive increase in respiratory flow and efforts that were clearly and systematically observed with breath resumption; accordingly, an overnight polysomnography was not performed. Transcutaneous $\mathrm{CO}_{2}$ levels were not measured. Oxygen during sleep $(2 \mathrm{~L} / \mathrm{min})$ was recommended, with no attempt to implement continuous positive airway pressure (CPAP) or bilevel positive airway pressure therapy, or adaptative servoventilation.

The outcome was unfavourable - tachypnea, low systemic blood pressure and severe metabolic acidosis were observed. A diagnosis of low cardiac output secondary to severe biventricular dysfunction was made. At the request of the patient and his family, active treatments were discontinued and death occurred $2 \mathrm{~h}$ later.

\section{Case 2}

The younger brother exhibited elevated creatine kinase levels (1300 units/L) and was suspected of having DMD. Genetic testing confirmed the diagnosis, showing the familial deletion of exons 12 and
13 of the dystrophin gene. Muscle biopsy was believed to be unnecessary. He was able to walk until he was 11 years of age and, at 17 years of age, was still able to move his arms against gravity. No systemic corticosteroid treatment was administered. At 12 years of age, LVEF was normal (64\%); at 15 years of age, LVEF was 55\%, and a diagnosis of mild dilated cardiomyopathy secondary to DMD was made. Lisinopril was started at $5 \mathrm{mg}$ daily. At the request of his mother, he was seen at 17 years of age, a few weeks after his brother's death. At that time, there was no complaint of respiratory symptoms. Physical examination revealed a normal body mass index with no obvious upper airway abnormalities (macroglossia, tonsil hypertrophy, retrognathia). Chest $\mathrm{x}$-ray and pulmonary function testing were normal (Table 1).

Echocardiography revealed a decreased LVEF (30\%) with mild left ventricular diastolic dilatation $(56 \mathrm{~mm})$. Beta-blocker (bisoprolol) was initiated and the dose was eventually increased to $5 \mathrm{mg}$ daily. Nocturnal oxymetry showed an oxygen desaturation index of $1 / \mathrm{h}$. His $\mathrm{SpO}_{2}$ was $>90 \%$ during the recording, with a mean value of $97 \%$. A full polysomnography revealed recurrent episodes of obstructive respiratory abnormalities (Figure 2). His apnea/hypopnea index was 26/h. Most of these anomalies were obstructive hypopneas. In REM sleep, the index increased to $64 / \mathrm{h}$. There were no significant desaturation and no central apneas. These obstructive events were corrected with a CPAP level of $10 \mathrm{cmH}_{2} \mathrm{O}$. At the final visit in 2010, the patient was in stable condition, with an unchanged LVEF.

\section{DISCUSSION}

These two DMD cases illustrate the diversity of sleep-related breathing disorders associated with DMD. While nocturnal and/or daytime hypoventilation related to respiratory muscle weakness is the most frequent respiratory manifestation seen in young adults with DMD (1), these two brothers had sleep-related breathing disorders that are less common in DMD: Cheynes-Stokes respiration with central apnea and OSA.

The clinical presentation of DMD in these two brothers was unusual. Although the diagnosis of DMD was firmly established by genetic testing and muscle biopsy (Case 1), the phenotypic expression of the disease was intermediate between DMD and a milder form of dystrophinopathy: Becker muscular dystrophy (BMD). Typically, a young adult with DMD is unable to produce any efficient muscle contraction of the extremities. At the end of the teenage years, 


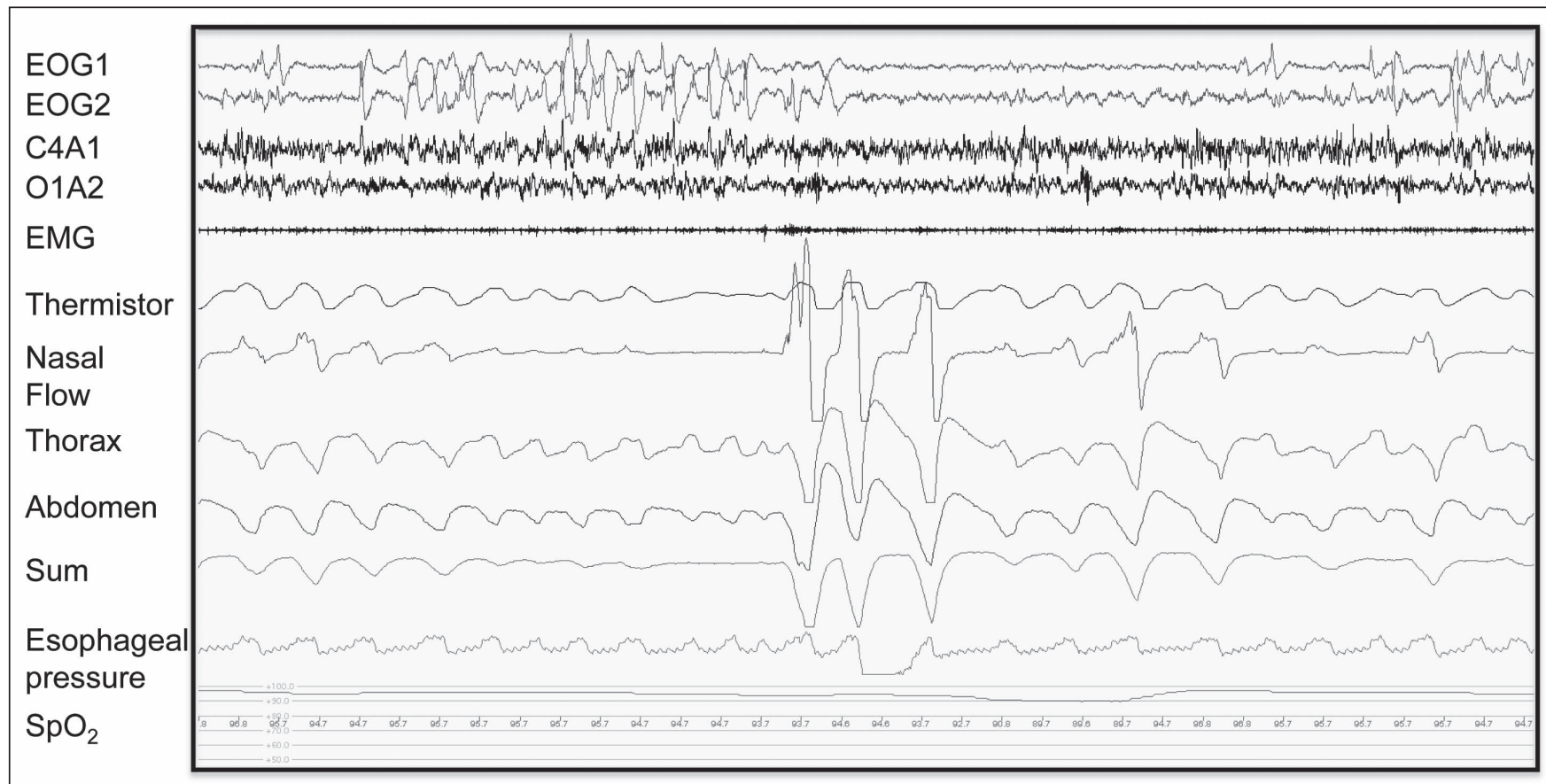

$30 \mathrm{sec}$

Figure 2) Representative full polysomnography recording revealing recurrent episodes of obstructive respiratory abnormalities with clear paradoxical chest wall movements during the hypopneic/apneic events that were not seen in breathing cycles preceding/following the respiratory events. This observation is important to exclude diaphragmatic weakness as a cause of paradoxical chest wall movements. Respiratory efforts were also maintained during flow drop, confirming the obstructive nature of this event. EMG Chin electromyogram; EOG Electrooculogram; $\mathrm{SpO}_{2}$ Pulse oxygen saturation

profound respiratory muscle weakness and severe restrictive respiratory impairment (vital capacity $<1 \mathrm{~L}$ ) is common. LVEF is usually mildly impaired. Inconsistent with this typical clinical picture, the two brothers had upper limb muscle strength and respiratory muscle function that were surprisingly well maintained for DMD patients of their age. In contrast to this relatively well preserved respiratory function, they exhibited an early onset of moderate-to-severe left ventricular systolic dysfunction secondary to DMD. In many ways, the clinical presentation of the two brothers was similar to what is usually observed in patients with BMD, in which cardiac disease is very common and is frequently out of proportion with skeletal muscle impairment.

Even though all forms of DMD are characterized by the same absence or almost complete absence of dystrophin, the underlying genetic abnormalities and the clinical expression of the disease are highly variable. Although the clinical portrait is influenced by the type of mutation affecting the DMD gene (7), the relationship between the precise genetic abnormality and the clinical presentation is complex and is only beginning to be elucidated. Recent research has attempted to identify a specific dystrophin gene mutation that would predict the risk of cardiac involvement. Deletions of exons $1(8,9) ; 4(10) ; 12$ (as in our two cases); 14 to $17 ; 31$ to 42 (11); 44 (12); and 48 to 49 (13) are predictive of cardiac disease. Understanding the mechanisms linking genetics and cardiac involvement in muscular dystrophies, however, requires further study.

The younger brother (Case 2) had pure OSA, a diagnosis that can sometimes be challenging in DMD. In this clinical situation, obstructive events could be misclassified as central events when weak respiratory muscles are unable to produce chest wall movements against closed upper airways (14). In our patient, the diagnosis of OSA was straightforward because he exhibited typical paradoxical chest wall movements during the apneic events. We speculated that this paradoxical movement was observed because of relatively well-preserved respiratory muscle strength. A retrospective study involving pediatric DMD patients showed a bimodal age distribution of sleep-related breathing disorders, with OSA usually found in the first decade of life, and hypoventilation being more commonly observed during the second decade of life (3). The prevalence of OSA can reach up to 30\% in young patients with DMD, a number significantly higher than the reported prevalence of $3 \%$ for the overall pediatric population (3). DMD can increase the risk of OSA because of the associated changes in upper airway anatomy (eg, macroglossia) or, as in Case 2, through the development of congestive heart failure, an important risk factor for OSA (15). Polysomnography is recommended in children with symptoms of OSA. Because OSA is frequently asymptomatic in DMD, a sleep investigation is also recommended even in the absence of symptoms, at the stage of wheelchair dependency $(1,3)$. In this context, and where available, overnight polysomnography is ideal. If polysomongraphy is not available or accessible, overnight pulse oxymetry may also provide useful information, although sleep-related breathing disorders that are not associated with oxygen desaturation will not be detected. The older brother suffered from classic Cheynes-Stokes respiration with central apnea in the context of his severe decompensated cardiomyopathy. This diagnosis was suspected on the basis of his medical history of left ventricular dysfunction and on a low daytime $\mathrm{PaCO}_{2}(16)$, a clinical finding that is very unusual in a 19 -year-old man with DMD.

Dilated cardiomyopathy, hypertrophic cardiomyopathy, arrhythmias and conduction abnormalities have all been reported in association with the dystrophinopathies. In DMD patients, cardiac involvement develops insidiously during the first decade of life, often when skeletal muscle weakness is already significant. Sinus tachycardia is present in most patients after five years of age and persists throughout life. In a cohort of DMD patients, conduction changes were observed by 10 years of age, mostly consisting of a prolonged QT interval (17). During the second decade of life, echocardiographic signs of cardiomyopathy (hypertrophic and dilated) develops. The incidence of cardiomyopathy is approximately $30 \%$ at 14 years of age and $50 \%$ at 18 years of age, and is almost universal after 18 years of age (17). The dilated form is the most common type of cardiomyopathy 
at all ages (17). Despite this high incidence, most patients with DMD remain asymptomatic probably because of a reduced cardiac workload in the wheelchair-bound state. Only 10\% to $20 \%$ of DMD patients will eventually die from cardiac disease. The cardiac evolution of patients with BMD seems to be worse than in those with DMD. Some authors suggest that the slow progression of muscle weakness in typical BMD patients permits a prolonged workload on an impaired myocardium, which eventually results in dilated cardiomyopathy. In fact, congestive heart failure is the most common cause of death in BMD, explaining up to $50 \%$ of its related mortality (18).

Cardiac disease should be diagnosed and treated early in DMD (5). DMD patients should undergo cardiac investigation at the time of diagnosis, before any surgery, every two years up to 10 years of age, and annually thereafter (18). Although less well studied than in ischemic heart disease, angiotensin-converting enzyme inhibitors and betablockers may also slow the progression of the disease in $\operatorname{DMD}(4,5,19)$. Treatments using systemic corticosteroids, which are often used to preserve peripheral skeletal muscle function, may also be of some benefit to protect heart function $(20,21)$. Cardiac transplantation is usually not an option in patients with DMD, but may be an acceptable treatment in those with BMD (22).

OSA should be specifically treated in patients with DMD. Although CPAP can be used, bilevel positive airway pressure is most commonly used to account for the eventuality of nocturnal and daytime hypoventilation (3). Apart from aggressive pharmacological treatment for heart failure, the best treatment for Cheyne-Stokes respiration

\section{REFERENCES}

1. Finder JD, Birnkrant D, Carl J, et al. Respiratory care of the patient with Duchenne muscular dystrophy: ATS consensus statement. Am J Respir Crit Care Med 2004;170:456-65.

2. Simonds AK, Muntoni F, Heather S, Fielding S. Impact of nasal ventilation on survival in hypercapnic Duchenne muscular dystrophy. Thorax 1998;53:949-52.

3. Suresh S, Wales P, Dakin C, Harris MA, Cooper DG. Sleep-related breathing disorder in Duchenne muscular dystrophy: Disease spectrum in the paediatric population. Paediatr Child Health 2005;41:500-3.

4. Duboc D, Meune C, Lerebours G, Devaux JY, Vaksmann G, Becane HM. Effect of perindopril on the onset and progression of left ventricular dysfunction in Duchenne muscular dystrophy. J Am Coll Cardiol 2005;45:855-857.

5. Duboc D, Meune C, Pierre B, et al. Perindopril preventive treatment on mortality in Duchenne muscular dystrophy: 10 years' follow-up. Am Heart J 2007;154:596-602.

6. Black LF, Hyatt RE. Maximal respiratory pressures: Normal values and relationship to age and sex. Am Rev Respir Dis 1969;99:696-702.

7. Bushby K, Finkel R, Birnkrant DJ, et al. Diagnosis and management of Duchenne muscular dystrophy, part 1: Diagnosis, and pharmacological and psychosocial management. Lancet Neurol 2010;9:77-93.

8. Oldfors A, Eriksson BO, Kyllerman M, Martinsson T, Wahlstrom J. Dilated cardiomyopathy and the dystrophin gene: An illustrated review. Br Heart J 1994;72:344-8.

9. Yoshida K, Ikeda S, Nakamura A, et al. Molecular analysis of the Duchenne muscular dystrophy gene in patients with Becker muscular dystrophy presenting with dilated cardiomyopathy. Muscle Nerve 1993;16:1161-6.

10. Saotome M, Yoshitomi Y, Kojima S, Kuramochi M. Dilated cardiomyopathy of Becker-type muscular dystrophy with exon 4 deletion - a case report. Angiology 2001;52:343-7.

11. Jefferies JL, Eidem BW, Belmont JW, et al. Genetic predictors and remodeling of dilated cardiomyopathy in muscular dystrophy. Circulation 2005;112:2799-804.

12. Todorova A, Constantinova D, Kremensky I. Dilated cardiomyopathy and new 16 bp deletion in exon 44 of the with central apnea in the context of congestive heart failure associated with DMD is uncertain, as is the case with other causes of heart failure (23). Supplemental oxygen, CPAP and bilevel positive airway pressure therapy, and adaptative servoventilation can be proposed according to the clinical situation (23). In the absence of clear therapeutic guidelines, and considering the need for a simple treatment at the request of the patient, we elected to use supplemental oxygen during the nighttime for our patient.

Female DMD and BMD carriers show a surprisingly high incidence of cardiac involvement that progresses with age and manifests primarily as cardiomyopathy (13). One study involving $152 \mathrm{DMD}$ and 45 BMD female carriers over a 10-year period (24), found that $41 \%$ of the women $>18$ years of age had a cardiomyopathy $(30 \%$ hypertrophic and $11 \%$ dilated). Approximately $8 \%$ of carriers also showed clinical signs of skeletal muscle disease. In another study (25), cardiac abnormalities were observed in only $18 \%$ of female carriers. These studies emphasize the high prevalence of cardiomyopathy in this population. Consequently, cardiac evaluation of DMD carriers is recommended every five years (18).

\section{CONCLUSION}

Although nocturnal and daytime hypoventilation is the most common respiratory complication observed in adults with DMD, clinicians should be aware that other sleep-related breathing disorders, such as OSA and Cheyne-Stokes respiration with central apnea, may also occur, particularly when cardiomyopathy is present.

dystrophin gene: The possible role of repeated motifs in mutation generation. Am J Med Genet A 2003;120A:5-7.

13. Nigro G, Politano L, Nigro V, Petretta VR, Comi LI. Mutation of dystrophin gene and cardiomyopathy. Neuromuscul Disord 1994;4:371-9.

14. Khan Y, Heckmatt JZ. Obstructive apnoeas in Duchenne muscular dystrophy. Thorax 1994;49:157-61.

15. Naughton MT, Bradley TD. Sleep apnea in congestive heart failure. Clin Chest Med 1998;19:99-113.

16. Yumino D, Bradley TD. Central sleep apnea and Cheyne-Stokes respiration. Proc Am Thorac Soc 2008;5:226-36.

17. Nigro G, Comi LI, Politano L, Bain RJ. The incidence and evolution of cardiomyopathy in Duchenne muscular dystrophy. Int J Cardiol 1990;26:271-77.

18. Bushby K, Muntoni F, Bourke JP. 107th ENMC international workshop: The management of cardiac involvement in muscular dystrophy and myotonic dystrophy. June 7 to 9, 2002, Naarden, The Netherlands. Neuromuscul Disord 2003;13:166-72.

19. Kajimoto H, Ishigaki K, Okumura K, et al. Beta-blocker therapy for cardiac dysfunction in patients with muscular dystrophy. Circ J 2006;70:991-4.

20. Markham LW, Spicer RL, Khoury PR, Wong BL, Mathews KD, Cripe LH. Steroid therapy and cardiac function in Duchenne muscular dystrophy. Pediatr Cardiol 2005;26:768-71.

21. Silversides CK, Webb GD, Harris VA, Biggar DW. Effects of deflazacort on left ventricular function in patients with Duchenne muscular dystrophy. Am J Cardiol 2003;91:769-72.

22. Komanapalli CB, Sera V, Slater MS, et al. Becker's muscular dystrophy and orthotopic heart transplantation: Perioperative considerations. Heart Surg Forum 2006;9:E604-6.

23. Arzt M, Bradley TD. Treatment of sleep apnea in heart failure. Am J Respir Crit Care Med 2006;173:1300-8.

24. Politano L, Nigro V, Nigro G, et al. Development of cardiomyopathy in female carriers of Duchenne and Becker muscular dystrophies. JAMA 1996;275:1335-8.

25. Grain L, Cortina-Borja M, Forfar C, Hilton-Jones D, Hopkin J, Burch M. Cardiac abnormalities and skeletal muscle weakness in carriers of Duchenne and Becker muscular dystrophies and controls. Neuromuscul Disord 2001;11:186-91. 


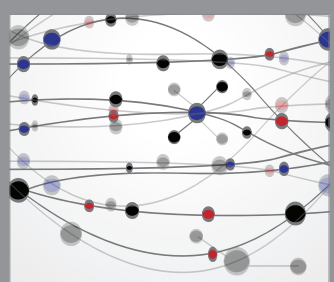

The Scientific World Journal
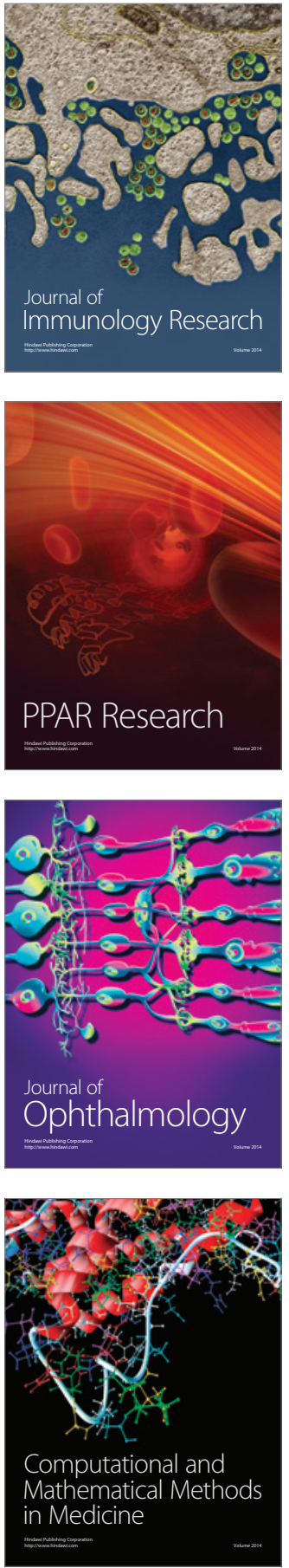

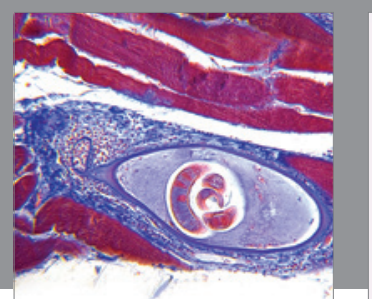

Gastroenterology Research and Practice

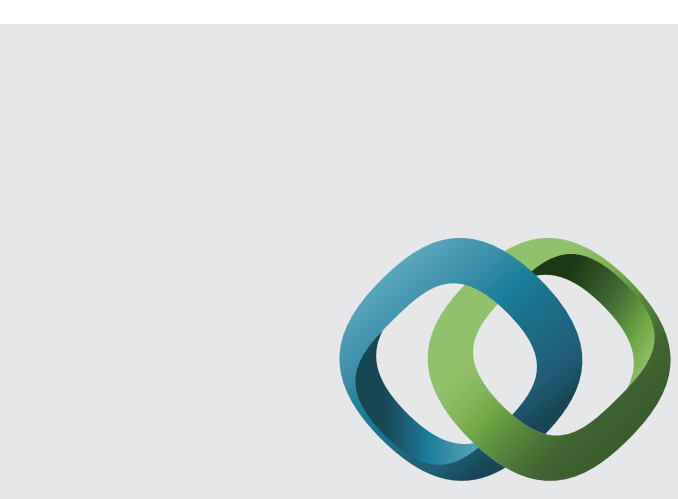

\section{Hindawi}

Submit your manuscripts at

http://www.hindawi.com
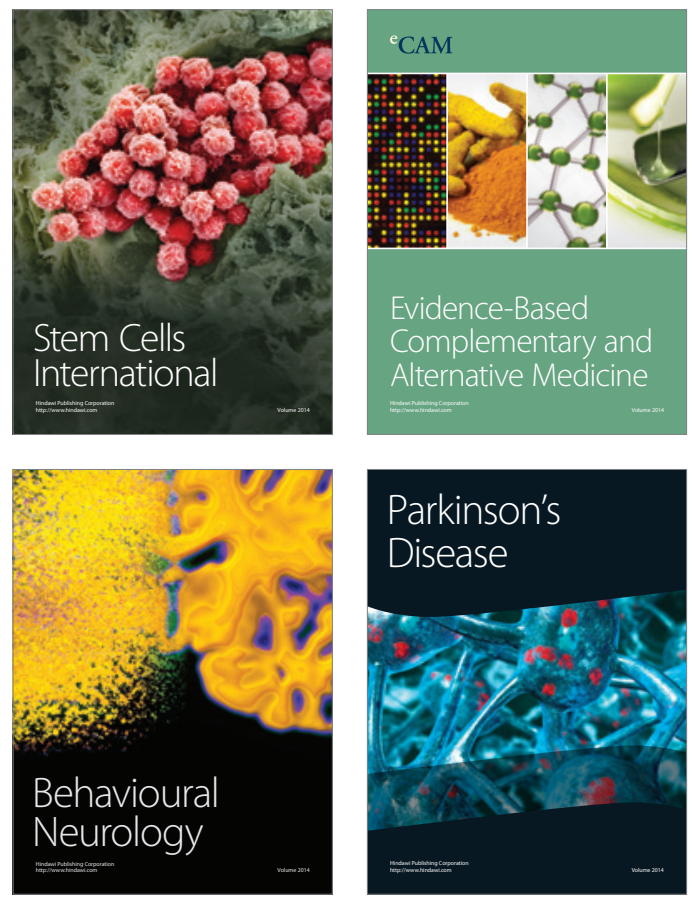
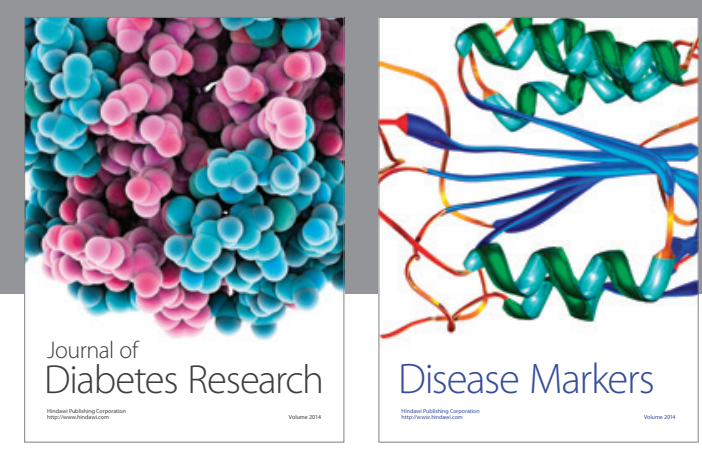

Disease Markers
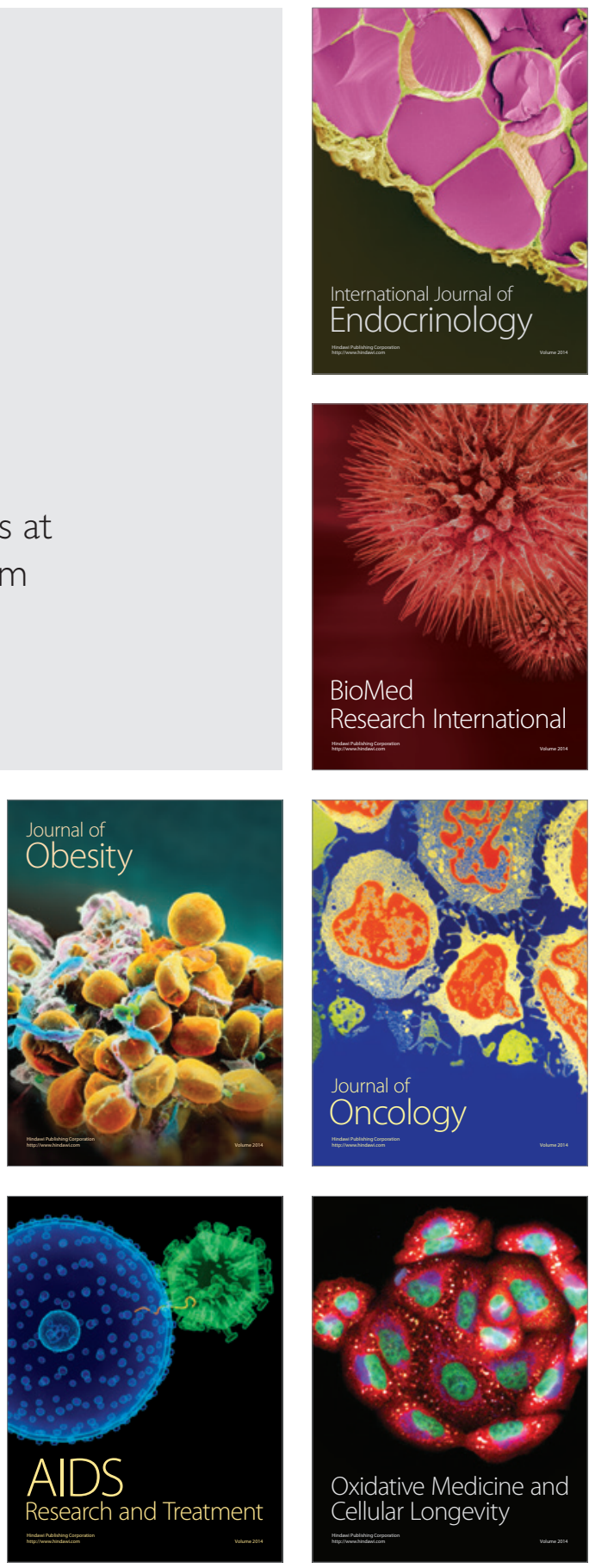